\section{要 旨}

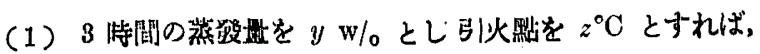

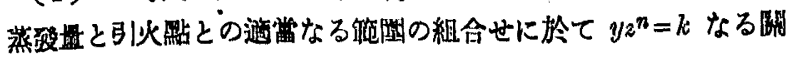
保式が成立子。

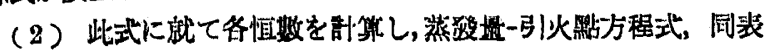
及圆を作成せり。

（3）從て引火點を知りて或温度に於ける葆酸量を是等の表,
画又は式によりて容易に求さることを得。

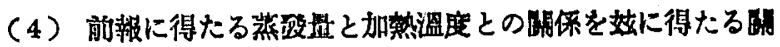

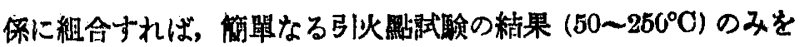

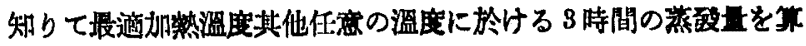
出し得るなり。

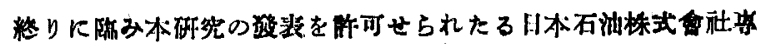

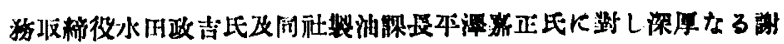
新を表す。

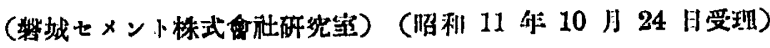

\title{
(II) $\mathrm{CaO} \cdot \mathrm{Fe}_{2} \mathrm{O}_{3}$ 及 $2 \mathrm{CaO} \cdot \mathrm{Fe}_{2} \mathrm{O}_{3}$ の合成と水和作用に就て
}

\section{畺田義彰}

酸化鐵と不灰との 2 成分系間に於ける䥫酸石灰監に就ては古く より研卶され（Wink'er 氏, Michaelis 氏 (Schmidt, Der Portlandzement, 67) 等を初めとし Le Chatelier 氏, Zulkowski 氏, Schott 氏, Hilpert 及 Kohlmeyer 氏 (Kiihl, Die Chemie der hydraulischen Bindemittel, 130), Sosman 及 Mervin 氏(Junr. Wash. Accul. Sci., 1916, 6, 532; Wilson, Ceramics-Clay Tech-

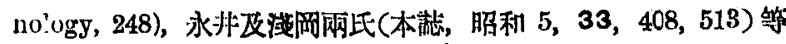
の研究を数ふるを得べし。之等の研究に依り酸化鐵と不湫の 2 成 分来间に於外る化合物は $\mathrm{CaO} \cdot \mathrm{Fe}_{2} \mathrm{O}_{3}$ と $2 \mathrm{CaO} \cdot \mathrm{Fc}_{2} \mathrm{O}_{3}$ の 2 化合 物の存在するる事湖確となれり。

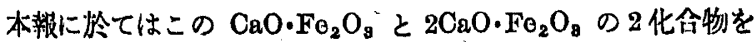
合成してこのもの」水和作用につき研究せるものを哌告せん。

\section{$\mathrm{CaO}_{\mathrm{Fe}} \mathrm{O}_{3}$ 及 $2 \mathrm{CaO} . \mathrm{Fe}_{2} \mathrm{O}_{3}$ の合成}

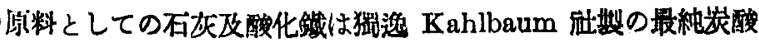

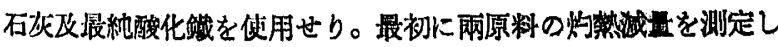
て後に雨原料を $\mathrm{OaO} \cdot \mathrm{Fe}_{2} \mathrm{O}_{8}$ 及 $2 \mathrm{CaO} \cdot \mathrm{Fe}_{2} \mathrm{O}_{8}$ になる樣に原料を

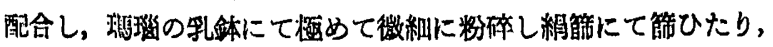

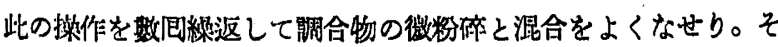

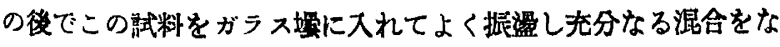
せり。この㚬一混合を終りたる睭合物に水を加一混捏し直俓約

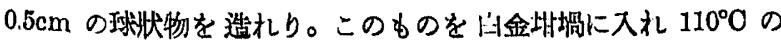

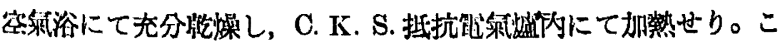

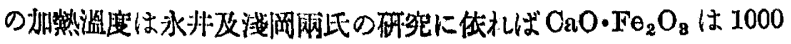
${ }^{\circ} \mathrm{C}$ 附近より徐々に化合し初め $1100 \sim 1150^{\circ} \mathrm{C}$ 附近にて急激に進 み $1200^{\circ} \mathrm{C}$ に於て憏憗小ると共に完全に化合するすのなりとされ

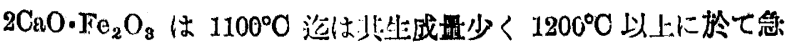

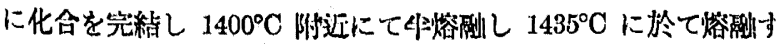

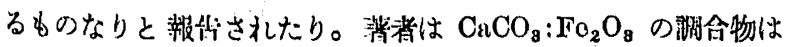
$1200^{\circ} \mathrm{C} に 3$ 時間, $2 \mathrm{CaCO}_{3}: \mathrm{Fe}_{2} \mathrm{O}_{3}$ の溯合物は $1400^{\circ} \mathrm{C} に 3$ 㭙間

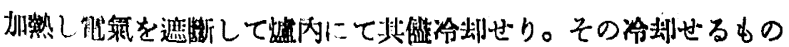

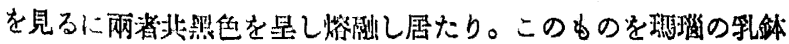
にて粉的し粉末たなせり。次に之等のもの〉化舉分析をなし迶離

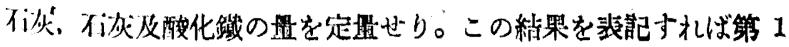
裴の如し。

\begin{tabular}{|c|c|c|c|c|c|}
\hline 第 1 表 & \multicolumn{5}{|c|}{$\begin{array}{l}\mathrm{CaCO}_{8}: \mathrm{Fe}_{2} \mathrm{O}_{3} \text { 及 } 2 \mathrm{CaCO}_{8}: \mathrm{Fe}_{2} \mathrm{O}_{8} \\
\text { の加熱物の化盆分析結果 }\end{array}$} \\
\hline 试 & 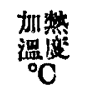 & $\begin{array}{l}\text { 遊噰 } \\
\text { 石灰 } \\
\%\end{array}$ & $\begin{array}{l}\text { 石底 } \\
\%\end{array}$ & $\begin{array}{l}\text { 鿾化 } \\
\% \\
\%\end{array}$ & $\begin{array}{l}\text { 化合せる石 } \\
\text { 长之酸化似 } \\
\text { ○分子比 }\end{array}$ \\
\hline $\begin{array}{c}\mathrm{CaCO}_{3}: \mathrm{Fe}_{2} \mathrm{O}_{\mathrm{s}} \\
\text { 加热物 }\end{array}$ & 1200 & 0.00 & 25.71 & 74.10 & 0.99 \\
\hline $\mathrm{CuCO}_{\mathrm{a}}: \mathrm{Fe}_{2} \mathrm{O}_{\mathrm{g}}$ & $14^{\prime} 0$ & 0.00 & 41.18 & 58.68 & 2.00 \\
\hline
\end{tabular}

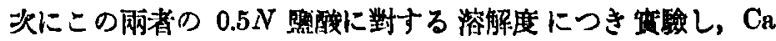
$\mathrm{CO}_{3}: \mathrm{Fe}_{2} \mathrm{O}_{3}$ 加䓡物は不溶, $2 \mathrm{CnCO}_{3}: \mathrm{Fe}_{2} \mathrm{O}_{3}$ 加熱物は可溶にして

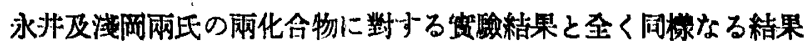
を得, $\mathrm{CaCO}_{8}: \mathrm{Fe}_{2} \mathrm{O}_{3}$ 加㷊物は $\mathrm{CaO} \cdot \mathrm{Fe}_{2} \mathrm{O}_{3}, 2 \mathrm{CuCO}: \mathrm{Fe}_{2} \mathrm{O}_{3}$

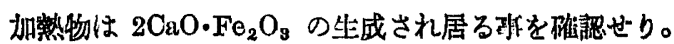

\section{$\mathrm{CaO} . \mathrm{Fe}_{2} \mathrm{O}_{3}$ 及 $2 \mathrm{CaO} . \mathrm{Fe}_{2} \mathrm{O}_{3}$ の水和作用}

$\mathrm{CaO} \cdot \mathrm{Fe}_{2} \mathrm{O}_{3}$ 歹 $2 \mathrm{CaO} \cdot \mathrm{Fe}_{2} \mathrm{O}_{3}$ の水和作用につき J. Konarzewski 氏 (Roczniki chem., 1931, 11) は研究し $\mathrm{CaO} \cdot \mathrm{Fe}_{2} \mathrm{O}_{3}$ は水と 作用せざれどす $2 \mathrm{CaO} \cdot \mathrm{Fe}_{2} \mathrm{O}_{3}$ は水と作用することを報告せり。

渚者は上敞に於て合成したる $\mathrm{CaO} \cdot \mathrm{Fe}_{2} \mathrm{O}_{3}$ 改 $2 \mathrm{CaO} \cdot \mathrm{Fe}_{2} \mathrm{O}_{3}$ の 粉末を內容 $50 \mathrm{cc}$ の硬䓄ガラス橓に $0.5 \mathrm{~g}$ 科取し之れに炭酸ガス を除去せる水溫 $25^{\circ} \mathrm{C}$ の浾䀺水 $50 \mathrm{cc}$ を注入しゴム栓をして之れ を $25^{\circ} \mathrm{O}$ の唒溫椹中にて振湦しつ小水和作用をなさしめたり。而 して ン，6，12，24，168，336 時間經過せるすのにつきその水和 作用の状態を测定せり り。その水和作用の狀熊は蒸溜水に溶出せる

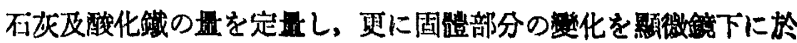
て检せり。次に蒸溜水に溶出せる石灰及酸化鐵の量を表記すれば 第 2 表の如し。

この絬果を見るに $\mathrm{CnO} \cdot \mathrm{Fe}_{2} \mathrm{O}_{3}$ は水中に溶出せる不灰及酸化銅

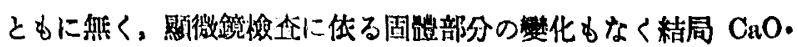
$\mathrm{Fe}_{2} \mathrm{O}_{3}$ は水和作用をなさざる壮を認めたり。

次に $2 \mathrm{CaO} \cdot \mathrm{Fe}_{2} \mathrm{O}_{3}$ は時間の經過に從ひ水中に溶沙せる石灰の

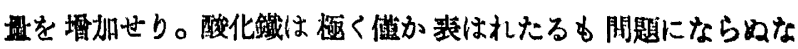

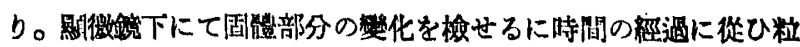
子の周图に透明性の水和物を多く生ぜり。之等の实飡桔果に传り $2 \mathrm{CaO} \cdot \mathrm{Fe}_{2} \mathrm{O}_{3}{ }^{\prime}$ は水と作用し段↔不灰の少き化合物に䢰移し， 
$2 \mathrm{CaO} \cdot \mathrm{Fe}_{2} \mathrm{O}_{3}+$ Water $\rightarrow \mathrm{Ca}(\mathrm{OH})_{2}+\mathrm{CaO} \cdot \mathrm{Fe}_{2} \mathrm{O}_{3} \mathrm{aq}$ の如く進行する事を苑めたり。

於て $\mathrm{CaO} \cdot \mathrm{Fe}_{2} \mathrm{O}_{3}$ は水と作用せざれどす $2 \mathrm{CaO} \cdot \mathrm{Fe}_{2} \mathrm{O}_{3}$ は

第 2 表 $\mathrm{CaO} \cdot \mathrm{Fe}_{2} \mathrm{O}_{3}$ 及 $2 \mathrm{CaO} \cdot \mathrm{Fe}_{2} \mathrm{O}_{3}$ の水和作用の進行狀態

\begin{tabular}{|c|c|c|c|}
\hline 試料 & $\begin{array}{l}\text { 水和作用 } \\
\text { の時閣 }\end{array}$ & $\begin{array}{l}\text { 溶出せる } \\
\text { 石灰の量 }\end{array}$ & $\begin{array}{l}\text { 溶出せる酸 } \\
\text { 化践の量 }\end{array}$ \\
\hline \multirow[t]{6}{*}{$\mathrm{CaO} \cdot \mathrm{Fe}_{2} \mathrm{O}_{3}$} & 2時 & $0.00 \%$ & $0.00 \%$ \\
\hline & 6 & " & " \\
\hline & 12 & 痕跡 & " \\
\hline & 24 & " & " \\
\hline & 168 & " & " \\
\hline & 336 & " & " \\
\hline \multirow{6}{*}{$2 \mathrm{CaO} \cdot \mathrm{Fe}_{2} \mathrm{O}_{3}$} & 2 & 6.31 & 疗跡 \\
\hline & 6 & 7.72 & " \\
\hline & 12 & 7.92 & 0.05 \\
\hline & 24 & 8.19 & 0.06 \\
\hline & 168 & 9.49 & 0.07 \\
\hline & 336 & 11.77 & 0.10 \\
\hline
\end{tabular}

水和作用をなすすのなることを明かに確認する事を得たり。<smiles>[124CH]</smiles>

本報に於ては $\mathrm{CaO} \cdot \mathrm{Fe}_{2} \mathrm{O}_{3}$ 及 $2 \mathrm{CaO} \cdot \mathrm{Fe}_{2} \mathrm{O}_{3}$ の合成とその合成 物の水和作用につき研究し次の如き結論を得たり。

(1) $\mathrm{CaCO}_{3}: \mathrm{Fe}_{2} \mathrm{O}_{3}$ の調合物を $1200^{\circ} \mathrm{C}$ に 3 㭙間加尛し $\mathrm{CaO}$. $\mathrm{Fe}_{2} \mathrm{O}_{3}$ なる化合物を得, $2 \mathrm{CaCO}_{3}: \mathrm{Fe}_{2} \mathrm{O}_{3}$ の調合物を $1400^{\circ} \mathrm{C}$ に 3 時間加熱し $2 \mathrm{CaO} \cdot \mathrm{Fe}_{2} \mathrm{O}_{3}$ なる化合物の得らる」事を認めたり。

(2) $\mathrm{CaO} \cdot \mathrm{Fe}_{2} \mathrm{O}_{3}$ 及 $2 \mathrm{CaO} \cdot \mathrm{Fe}_{2} \mathrm{O}_{3}$ の粉末にせるもの小水和 作用につき研究し $\mathrm{CaO} \cdot \mathrm{Fe}_{2} \mathrm{O}_{3}$ は水和作用をなさざれども $2 \mathrm{CaO}$. $\mathrm{Fe}_{2} \mathrm{O}_{3}$ は水和作用をなし

$2 \mathrm{CaO} \cdot \mathrm{Fe}_{2} \mathrm{O}_{3}+$ Water $\rightarrow \mathrm{Ca}(\mathrm{OH})_{2}+\mathrm{CaO} \cdot \mathrm{Fe}_{2} \mathrm{O}_{3}$ aq

の如く進行する事を認めたり。

附記 本研究を發表するに掌り東京工業大學数授近藤清治妱士

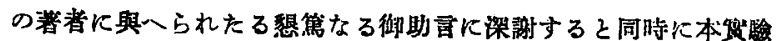
に熱心なる御助力を賜はりし荒尾泪四郎君に對し感謝の意を表 す。

（船城ヒメント株式會社研究宝）（昭和 11 年 10 月 30 日受理）

\title{
（12）ポルトランドセメントの苦土に關する研究 (第 2 報)
}

\section{鐵啭こ石灰の合成に於ける苦土の影暗}

\author{
真田義彰・西軍吉
}

著者は本報，第1 報に於て鐵酸苦土醷の合成に就き報告せ り。本報に於ては鐵转二石灰の合成に於ける苦土の影㮣につき截 告せん。

酸化鐡と石灰との 2 成分の間に於ては $\mathrm{CaO} \cdot \mathrm{Fe}_{2} \mathrm{O}_{3}$ 及 $2 \mathrm{CaO}$. $\mathrm{Fe}_{2} \mathrm{O}_{\mathrm{a}}$ の 2 化合物の存在する事が一般に認められ,佾この生成溫 度に就てる既に知られて居る。摔に著者は $\mathrm{CaO} \cdot \mathrm{Fe}_{2} \mathrm{O}_{3}$ 及 $2 \mathrm{CaO}$. $\mathrm{Fe}_{2} \mathrm{O}_{8}$ の合成につき研究し, $\mathrm{CaO} \cdot \mathrm{Fe}_{2} \mathrm{O}_{3}$ は $1200^{\circ} \mathrm{C}, 2 \mathrm{CaO} \cdot \mathrm{Fe}_{2} \mathrm{O}_{3}$ は $1400^{\circ} \mathrm{C}$ に於て合成せらるっことを認めたり。

此虎に於てはこの鐵酸二石灰の合成に當り苦土が如何なる影望 を成するのかに就き研究せり。

\section{苦土が存在する時の鐵酸二石灰の合成}

原料としての石灰, 酸化鐵及苦土は獨递 Kablbaum 社製の最 純炭酸石灰，酸化鐵及苦土を使用せり。

原料の配合は
A. $2 \mathrm{CaCO}_{3}: \mathrm{Fe}_{2} \mathrm{O}_{3}$ の割合より石灰分を不足にせるものに $\mathrm{MgO}$ の 1 分子を加へたるすの
B. $2 \mathrm{CaCO}_{3}: \mathrm{Fe}_{2} \mathrm{O}_{3}$ の制合より不灰分を過剩にせるすのに $\mathrm{MgO}$ の 1 分子を加へたるもの

の 2 梗類の混合物を造れり。

夷に炭酸石灰，酸化鐵及苦土の配合割合を表記すれはば第 1 表の 如し。

第 1 表の如き配合割合に各原料を 混合して本報，第 1 報の $\mathrm{MgO} \cdot \mathrm{Fe}_{2} \mathrm{O}_{3}$ の合成の場合と同樣の方法に依り原料を均一に混合 し水にて混揑して底遇の一邉 $10 \mathrm{~mm}$ ，高さ $30 \mathrm{~mm}$ の三角錐を製

\section{第 1 裴 缐料の配合割合}

\begin{tabular}{|c|c|c|c|c|c|c|}
\hline \multirow{2}{*}{ 試 } & \multicolumn{5}{|c|}{ 配 合 } & \\
\hline & 重 & 量 此 & & & 重量百分准 & \\
\hline & 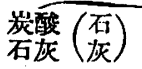 & 酸化 & $\begin{array}{l}\text { 㸃 } \\
\text { 圭 }\end{array}$ & $\begin{array}{l}\text { 石 } \\
\text { 灰 }\end{array}$ & 酸化 & $\begin{array}{l}\text { 胋 } \\
\text { 土 }\end{array}$ \\
\hline & 357 (200) & 396 & $\overline{100}$ & 28.7 & 56.9 & 14.4 \\
\hline & $536(300)$ & 396 & 100 & 37.7 & 49.7 . & 126 \\
\hline
\end{tabular}

形し, 自然乾燥の後空氣浴中にて充分に乾燥し，C.K.S. 雪氣敃 抗盧內に入れ $800^{\circ}, 1000^{\circ}, 1200^{\circ}$ 及 $1400^{\circ} \mathrm{C}$ 等の备溫度にて 2

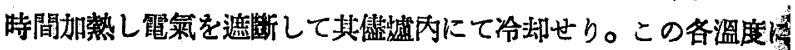
加熱せるすの〉化學分析結果と外觀を表記すれば第 2 表の如し。

\section{第 2 表 加熱物の化學分析結果と外觀}

\begin{tabular}{|c|c|c|c|c|c|}
\hline $\begin{array}{l}\text { 溫度 } \\
{ }^{\circ} \mathrm{C}\end{array}$ & $\begin{array}{c}\text { 時間 } \\
\text { 時 }\end{array}$ & 石庆 & 酸化鐡 & 苦土 & 加熱物の外 \\
\hline 800 & 2 & 29.17 & 56.55 & 14.04 & 淡黙褐色 \\
\hline 1000 & 2 & 29.14 & 56.47 & 14.12 & 黑褐色, 煟楴れり \\
\hline 1200 & 2 & 29.08 & 56.48 & 14.16 & 黑䄍色，硬〈㶿檞れり \\
\hline 1400 & 2 & 29.15 & 56.52 & 14.10 & 黑襢色, 烚骶せり \\
\hline 800 & 2 & 38.05 & 49.24 & 12.48 & 淡照褐色，㮖加䛜䋨れ \\
\hline 1000 & 2 & 38.11 & 49.20 & 19.48 & 淡篤袺色, 烧楴れり \\
\hline 1200 & 2 & 38.14 & 49.15 & 12.45 & 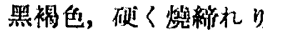 \\
\hline 1400 & $\mathbf{2}$ & 38.13 & 49.22 & 12.51 & 㑒钫せり \\
\hline
\end{tabular}

遊離石灰及遊離苦土の定量法

上記に於て加熱せる各試料の化合淮行狀態を遊離石右と遊雄苦 土の界を定量して知らんとせり。 